\title{
Índice de pobreza multidimensional en un municipio de Oaxaca
}

\section{Multidimensional Poverty Index in a municipality of Oaxaca}

\section{Índice de pobreza multidimensional em um município de Oaxaca}

Martha Jiménez García

Instituto Politécnico Nacional, México

majimenez@ipn.mx

https://orcid.org/0000-0002-8556-2955

Ingrid Anai Hernández Horta

Colegio de Postgraduados, México

hernandez.ingrid@colpos.mx

https://orcid.org/0000-0002-0299-5684

María Elena Tavera Cortes

Instituto Politécnico Nacional, México

mtavera@ipn.mx

https://orcid.org/0000-0002-2179-2735

\section{Resumen}

La pobreza ha sido un problema a nivel mundial, el cual en México se ha presentado con mayor incidencia en los estados del sur. El objetivo de este trabajo fue elaborar el índice multidimensional de pobreza con la inclusión de las tecnologías de información y comunicación para generar una intervención pública, disminuir la pobreza y mejorar el bienestar, enfocado en salud, nutrición, características de la vivienda, equipos de tecnologías de información y comunicación, internet, redes sociales y saneamiento. La investigación se llevó a cabo en el municipio de Tepelmeme Villa de Morelos del estado de Oaxaca. Para ello, se aplicó una encuesta de pobreza a 128 hogares en tres comunidades rurales y se elaboró un 


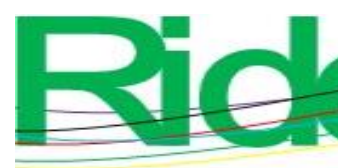

Revista Iberoamericana para la Investigación y el Desarrollo Educativo ISSN 2007 - 7467

índice multidimensional de pobreza con la metodología de Alkire y Foster. En los resultados se encontró un índice de 0.431 para una línea de pobreza de 50 \%. Los indicadores que contribuyeron a la pobreza en mayor cantidad fueron equipamiento del hogar $(15.21 \%$ para número de aparatos eléctricos, y $14.77 \%$ para automóvil), salud (7.76 \% para visita al médico especialista y $6.49 \%$ para visita al médico general), y nutrición (7.51\% para proteína, $6.3 \%$ para vegetales y $5.1 \%$ para frutas). Asimismo, se realizó una simulación de una intervención pública del gobierno, para lo cual se ajustaron los valores de los indicadores de pobreza con mayor contribución al índice y se volvió a calcular el índice de pobreza. Con esto se logró disminuir el índice multidimensional de pobreza a un valor de 0.355. Se concluyó que se debe hacer una intervención del gobierno para realizar una reasignación de recursos, por lo que se planteó un escenario para disminuir la pobreza.

Palabras clave: comunidad rural, índice de pobreza, salud, Tepelmeme, TIC.

\section{Abstract}

Poverty has been a problem worldwide and in Mexico it has occurred in greater numbers in the southern states. The objective of this work was to prepare the Multidimensional Poverty Index with the inclusion of information and communication technologies, to generate a public intervention and reduce poverty and improve well-being, focused on health, nutrition, characteristics of housing, equipment of information and communication technologies, internet, social networks, and sanitation. The research was carried out in the municipality of Tepelmeme Villa de Morelos in the state of Oaxaca, a poverty survey was applied to 128 households in three rural communities and a multidimensional poverty index was prepared with the Alkire and Foster methodology based on indicators of poverty. In the results, an index of 0.431 was found for a poverty line of $50 \%$, the indicators that contributed to poverty in greater quantity were household equipment with $15.21 \%$ (number of electrical appliances) and $14.77 \%$ (automobile), of equal health forms with $7.76 \%$ (visit to the specialist doctor) and $6.49 \%$ (visit to the general practitioner), in terms of nutrition with $7.51 \%$ (protein), $6.3 \%$ (vegetables), and 5.1 (fruits). Likewise, a simulation of a public government intervention was carried out, for this the values of the poverty indicators with the greatest contribution to the index were adjusted and the poverty index was recalculated, with this it was possible to reduce the multidimensional poverty index to a value of 0.355 . It was concluded that a 


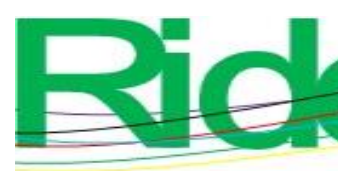

Revista Iberoamericana para la
Investigación y el Desarrollo Educativo
ISSN $2007-7467$

government intervention should be made to reallocate resources, so a scenario was proposed to reduce poverty.

Keywords: rural community, index poverty, health, Tepelmeme, ICT.

\section{Resumo}

A pobreza tem sido um problema mundial, o que no México ocorre com maior incidência nos estados do sul. O objetivo deste trabalho foi elaborar o índice multidimensional de pobreza com a inclusão de tecnologias de informação e comunicação para gerar uma intervenção pública, reduzir a pobreza e melhorar o bem-estar, com foco na saúde, nutrição, características de habitação, equipamentos de tecnologia de informação e comunicação, internet, redes sociais e saneamento. A investigação foi realizada no município de Tepelmeme Villa de Morelos, no estado de Oaxaca. Para fazer isso, uma pesquisa de pobreza foi aplicada a 128 famílias em três comunidades rurais e um índice de pobreza multidimensional foi preparado usando a metodologia de Alkire e Foster. Nos resultados, um índice de 0,431 foi encontrado para uma linha de pobreza de 50\%. Os indicadores que mais contribuíram para a pobreza foram equipamentos domésticos $(15,21 \%$ para o número de eletrodomésticos e 14,77\% para o automóvel), saúde (7,76\% para as visitas ao médico especialista e 6,49\% para as visitas ao clínico geral ) e nutrição (7,51\% para proteínas, 6,3\% para vegetais e $5,1 \%$ para frutas). Da mesma forma, foi realizada uma simulação de uma intervenção do governo público, para a qual foram ajustados os valores dos indicadores de pobreza com maior contribuição para o índice e o índice de pobreza foi recalculado. Com isso, o índice de pobreza multidimensional foi reduzido para o valor de 0,355. Concluiu-se que deveria ser feita uma intervenção governamental para realocar recursos, então foi proposto um cenário de redução da pobreza.

Palavras-chave: comunidade rural, índice de pobreza, saúde, Tepelmeme, TIC.

Fecha Recepción: Agosto 2020

Fecha Aceptación: Febrero 2021 


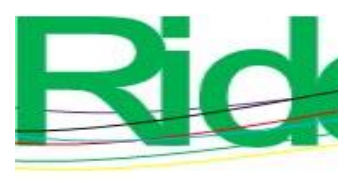

Revista Iberoamericana para la
Investigación y el Desarrollo Educativo ISSN 2007-7467

\section{Introducción}

En México, la pobreza es un problema histórico que se ha procurado atender a partir de iniciativas tanto nacionales como internacionales fomentadas por instituciones como el Banco Mundial, la Comisión Económica para América Latina y el Caribe, y la Organización de las Naciones Unidas (Aguilar-Estrada, Caamal-Cahuicho y Portillo-Vázquez, 2018a). Hace algunos años, en el país se definían tres líneas de bienestar para ubicar a la población con ingreso insuficiente: pobreza alimentaria, pobreza de capacidades y pobreza patrimonial (Aguilar Estrada et al., 2018b). Sin embargo, desde 2008, la pobreza se ha empezado a medir con un método multidimensional a cargo del Consejo Nacional de Evaluación de la Política de Desarrollo Social, organismo que - con base en la información proporcionada por el Instituto Nacional de Estadística y Geografía - ha realizado la estimación multidimensional de la pobreza 2008-2018. Esta información recabada resulta muy útil para el gobierno mexicano, pues le permite planificar sus intervenciones en cuanto a desarrollo social; además, el aspecto multidimensional promovido por México ha sido utilizado a nivel internacional para la construcción de la Agenda 2030 en lo referido a la reducción de la pobreza (Consejo Nacional de Evaluación de la Política de Desarrollo Social [Coneval], 2019).

Al respecto, es necesario señalar que el combate a la pobreza debe ser una prioridad, pues las consecuencias económicas generadas por la actual pandemia podrían incrementarla en $8 \%$ aproximadamente. Esto significa que en los últimos treinta años sería la primera que la pobreza aumenta de forma considerable, lo que acentuaría aún más el sufrimiento del 10 $\%$ de la población mundial que ya vive en situación de extrema pobreza, con dificultades para satisfacer sus necesidades básicas de salud, educación, acceso a agua y saneamiento (Naciones Unidas, 2020). Por eso, este fenómeno debe ser medido de forma multidimensional, en términos de déficits de atributos de bienestar a partir de niveles mínimamente aceptables para diferentes individuos en una sociedad (Alkire, Apablaza, Chakravarty y Yalonetzky, 2017).

Ahora bien, aunque México fue un pionero mundial en la implementación de un sistema oficial de medición de la pobreza multidimensional (Clausen, Vargas y Barrantes, 2019), no ha incluido la dimensión de tecnologías de información y comunicación (TIC), a pesar de que desde la década de 1990 las TIC han sido reconocidas como facilitadoras del desarrollo y reducción de la pobreza en todo el mundo (Becerril-Velasco, 2020). 


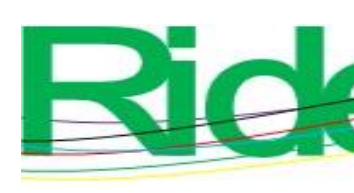

Revista Iberoamericana para la Investigación y el Desarrollo Educativo ISSN $2007-7467$

Por eso, el principal aporte de esta investigación es ofrecer un índice para las comunidades rurales que pueden emplear las TIC, ya que el avance tecnológico ha sido constantemente relacionado con el desarrollo económico, político y social, de ahí que los gobiernos de todo el mundo se hayan interesado en promover, en mayor o menor medida, la adopción de tecnología (Becerril-Velasco, 2020).

La investigación que se presenta se realizó en el municipio de Tepelmeme Villa de Morelos, Oaxaca, donde se estudiaron tres comunidades. Vale destacar que en el estado de Oaxaca el número de personas en situación de pobreza pasó de 2.8 millones a 2.7 millones entre 2016-2018. Esta última cifra, sin embargo, es superior a la reportada en 2008, cuando se habían registrado 2.3 millones de personas en situación de pobreza. Asimismo, entre 2016 y 2018 el acceso a los servicios de salud pasó de $15.9 \%$ a $16.3 \%$, los espacios de la vivienda pasaron de $26.3 \%$ a $25.1 \%$, y el acceso a la alimentación pasó de $31.4 \%$ a $27.9 \%$ (Coneval, 2019).

Ahora, en el caso específico del municipio de Tepelmeme Villa de Morelos, $77.8 \%$ de la población se halla en situación de pobreza, $21.7 \%$ tiene carencias en cuanto a calidad y espacios de vivienda, $65.9 \%$ presenta dificultades en lo concerniente a servicios básicos, $15.4 \%$ tiene deficiencias para el acceso a los servicios de la salud, $83.6 \%$ carece del acceso a la seguridad social, y 10.9 \% presenta problemas relacionados con la alimentación (Coneval, 2015).

Explicado lo anterior, el objetivo de este trabajo fue elaborar un índice multidimensional de pobreza, con la inclusión de las TIC, en una comunidad rural que se encuentra en situación de pobreza con el fin de procurar generar una intervención pública que permita aumentar el bienestar en salud, nutrición, vivienda, TIC y saneamiento. La intención es que con una intervención pública adecuada y basada en cálculos del índice de pobreza multidimensional se pueda cambiar esta realidad.

\section{Literatura relacionada con la pobreza}

Pobreza en México

Pese a los esfuerzos y a las políticas por apoyar a México, el país todavía sigue siendo una nación de mayoritariamente pobres, pues los niveles de vida adecuados solo se garantizan para $27.5 \%$ de la población mexicana. De hecho, la población en pobreza supera 2.3 veces a la considerada como clase media (Teruel, Reyes, Minor y López, 2018). Además, existe 


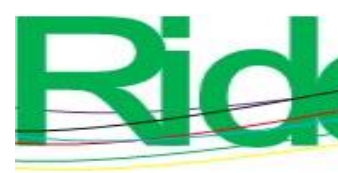

Revista Iberoamericana para la Investigación y el Desarrollo Educativo ISSN $2007-7467$

evidencia de que en los estados del sur de México los niveles de pobreza son aún mayores (Campos Vázquez y Monroy-Gómez-Franco, 2016).

Aunque la pobreza se extiende a todos los países del orbe, su incidencia es mayor en el medio rural (Chávez y Carrera, 2016). La pobreza rural en México surge principalmente de la falta de acceso a los servicios básicos (Huerta Barrientos, Vera Morales y Vázquez González, 2018), por lo que es importante ofrecer soluciones que permitan mejorar sus condiciones (Long, Hanlon y Pellegrin, 2018). Sin embargo, la realidad demuestra que estas zonas se encuentran en desventaja en cuanto a infraestructura y aplicaciones de telecomunicaciones, lo cual restringe sus posibilidades para crecer económica y socialmente (Roberts, Beel, Philip y Townsend, 2017). En tal sentido, se deben considerar los indicadores de las comunidades rurales, pues estos juegan un papel importante para la sostenibilidad y el desarrollo rural (Nguyen y Wells, 2018). Además, cuando se ayuda a determinado municipio se genera un efecto dominó que beneficia a las localidades aledañas (Leija y Saltillo, 2019). La capacidad para disminuir la pobreza en México, por tanto, se encuentra relacionada con las condiciones en materia de desigualdad, provisión de bienes públicos, estructura productiva y generación de empleos formales (Campos Vázquez y Monroy-Gómez-Franco, 2016).

\section{Pobreza multidimensional}

Una persona se encuentra en situación de pobreza multidimensional cuando no tiene garantizado el ejercicio de al menos uno de sus derechos para el desarrollo social (alimentación, salud, educación, vivienda, servicios básicos y seguridad social), y cuando sus ingresos son insuficientes para adquirir los bienes y servicios que requiere para satisfacer sus necesidades (Aguilar Estrada et al., 2018a).

En Pakistán, se realizó un estudio de pobreza multidimensional en áreas rurales; para ello, asociaron los niveles de vida, los activos agrícolas y no agrícolas, y los indicadores ambientales. Asimismo, se identificó que $44 \%$ de los hogares en las zonas rurales viven en los niveles más pobres, pues deben soportar la falta de agua potable, las inadecuadas instalaciones de saneamiento, las malas condiciones de vivienda, las fuentes de energía contaminadas y la privación de recursos económicos (Padda y Hameed, 2018).

Esta es una situación que también afecta a algunos países europeos, como Reino Unido, Hungría o Alemania, aunque sus particularidades sean diferentes, de ahí que sea difícil establecer comparaciones transnacionales. Por ello, la conceptualización teórica de la 


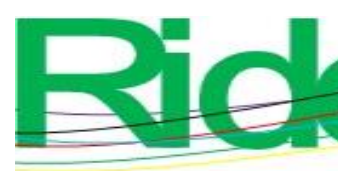

Revista Iberoamericana para la
Investigación y el Desarrollo Educativo
ISSN $2007-7467$

pobreza debe prever las desigualdades espaciales y socioculturales para ajustarla a los diferentes contextos regionales y nacionales (Bernard, Contzen, Decker y Shucksmith, 2019). Por ejemplo, la pobreza rural en los hogares de China se basa en las características demográficas, las variables de dotación de capital y las características geográficas (las variables de capital incluyen capital natural, capital físico, capital humano y capital financiero, y son factores vitales que afectan la pobreza de los agricultores) (Liu, Wei, Xu, Li y Li, 2019).

\section{Pobreza en comunidades rurales}

Los pueblos indígenas de América Latina presentan una mayor incidencia de la pobreza debido al despojo de sus tierras, lo que ha generado que sean menores sus niveles de ingreso, escolaridad, esperanza de vida y acceso al saneamiento y al agua potable (Comisión Económica para América Latina y el Caribe [Cepal], 2013). Debido a la existencia de tatas variables, es importante desarrollar investigaciones sobre la pobreza que incluyan los siguientes puntos: 1) ciclo de vida de la evolución de las áreas de pobreza; 2) medición de la pobreza regional multidimensional; 3) identificación geográfica de la pobreza y sus tipos de área, así como el patrón espacio-temporal; 4) simulación dinámica de la pobreza y su mecanismo; 5) mapeo de la pobreza; 6) determinación de la mejor escala geográfica para el combate a la pobreza, las medidas contra la pobreza, y 7) evaluación de la efectividad para la reducción de la pobreza (Zhou y Liu, 2019).

\section{Pobreza y alimentación}

Las madres fungen como guardianes de la salud de las generaciones futuras; sin embargo, el comportamiento de ellas está determinado por el conocimiento y las intenciones individuales, el contexto familiar y de vivienda, y las influencias comunitarias de la pobreza y la ruralidad, pues las madres rurales de bajos ingresos se benefician principalmente del apoyo de múltiples niveles de los programas de educación nutricional, agencias comunitarias y políticas públicas que fomentan la nutrición saludable y las prácticas alimentarias (Sano, Routh y Lanigan, 2019).

Los factores clave en la pobreza alimentaria son el tamaño grande de los hogares, el desempleo y los bajos niveles de educación inicial, de ahí que se deban crear programas bien articulados que garanticen el acceso a la educación, así como oportunidades laborales bien remuneradas (Eigbiremolen y Ogbuabor, 2018). 


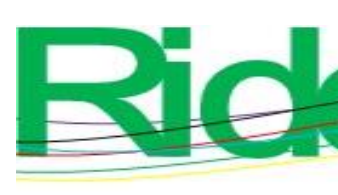

Revista Iberoamericana para la Investigación y el Desarrollo Educativo ISSN $2007-7467$

\section{Pobreza y TIC}

Las redes sociales han creado muchas oportunidades para los comerciantes de productos forestales no maderables y han ayudado a las personas a mitigar y salir de la pobreza. Esos recursos tecnológicos pueden ser informales o creados por distintas ONG o agencias gubernamentales con el propósito de elaborar redes de seguridad de apoyo práctico y financiero, o para ayudar en la comercialización de productos. Una muestra de esto en México es el caso de los recolectores de palma, los cuales se unieron voluntariamente y obtuvieron mejores precios de intermediarios para exportar dicho producto a Estados Unidos y Europa. Esto demuestra que las redes sociales pueden contribuir a la reducción de la pobreza, pues permite a los productores conseguir precios más justos (Pullanikkatil, 2019).

De igual forma, para las comunidades rurales que realizan actividades de agricultura el uso de las TIC es cada vez más necesario, ya que pueden recabar información útil para sus cosechas (Mittal y Mehar, 2016). En este sentido, pueden revisar el pronóstico de las sequias y unirse para impulsar políticas que permitan fomentar la inversión en programas de suministro de agua (Liu, Wenxin, Zhao y Xu, 2018).

La digitalización y la automatización, por otra parte, pueden mejorar significativamente la vida de los agricultores y trabajadores, y pueden generar nuevas oportunidades de empleo en el sector agrícola digital. Para esto, sin embargo, también se deben emprender acciones en cuanto a la capacitación tecnológica (Rotz et al., 2019). En pocas palabras, el acceso a dichos recursos no tendrá sentido si las personas no son capaces de sacarles el mayor provecho, por lo que se requiere promover el desarrollo de ciertas competencias digitales que permitan hacerlo (Van Dijk, 2017).

En concordancia con esta idea, el Estado mexicano ha realizado un gran esfuerzo para fortalecer el sector de las telecomunicaciones y abrir el acceso a las TIC. Además, las TIC están comenzando a implementarse en las políticas de lucha contra la pobreza en México, aunque vale acotar que estas iniciativas aún tienen que llegar al mercado laboral para que los pobres puedan aumentar su economía con las TIC (Becerril-Velasco, 2019).

A pesar de los beneficios económicos que las TIC ofrecen, resulta completamente un desafío fortalecer la infraestructura rural y las redes de comunicación para reducir las asimetrías de información y mejorar el acceso de los agricultores a los mercados, a través del comercio electrónico y plataformas de negociación, pues se debe superar la brecha geográfica y cultural para unir a productores y consumidores en un espacio virtual y de asistencia técnica colaborativa. En pocas palabras, es necesario unir esfuerzos con organizaciones no 

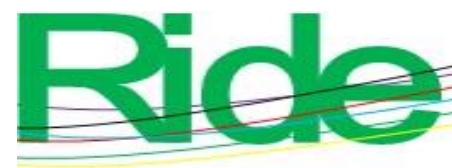

Revista Iberoamericana para la Investigación y el Desarrollo Educativo ISSN 2007 - 7467

gubernamentales, el sector privado y las instituciones de investigación para garantizar la sostenibilidad de los pequeños productores en zonas rurales (Hissa et al., 2019).

\section{Método}

La investigación se realizó en el año 2018 en 128 hogares (de una población de 318 hogares) del municipio de Tepelmeme Villa de Morelos, Oaxaca, específicamente en tres comunidades rurales: La Unión, Las Flores y Tepelmeme. De igual forma, se elaboró la creación de perfiles para cada hogar, los cuales fueron seleccionar las comunidades de estudio y que el hogar fuera habitado de forma permanente por los ocupantes. Para elaborar el índice multidimensional de pobreza se utilizó la metodología de Alkire y Foster (2011), la cual consistió en lo siguientes pasos, los cuales se presentan en forma de secciones a través del texto.

\section{Seleccionar las dimensiones, indicadores y pesos}

Se realizaron pruebas de asociación por la medida de Cramer's V y de redundancia por la prueba de Ro para la interrelación de todas las variables de la encuesta; posteriormente, se tomaron siete dimensiones: salud, equipo del hogar, nutrición, saneamiento, uso del internet, TIC y vivienda. Cada dimensión incluye indicadores que se describen en la tabla 1, mientras que en la figura 1 se presenta su relación. De igual forma, se establecieron ponderaciones para cada dimensión e indicador. La suma de dichas ponderaciones sumaron igual a uno (ecuación 1), lo cual normaliza las ponderaciones de los indicadores.

$$
\Sigma_{j} p_{j}=1(\mathbf{1})
$$

\section{Establecer límites de privación}

Se estableció el límite de la carencia para cada indicador, lo cual se muestra en la tabla 1 (columna descripción). 

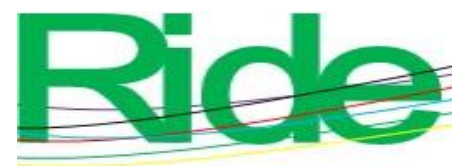

Revista Iberoamericana para la Investigación y el Desarrollo Educativo ISSN $2007-7467$

\section{Establecer un límite de pobreza multidimensional para identificar quién es pobre}

Se elaboró una matriz con los indicadores de la tabla 1. A quienes rebasaron el límite de la carencia por indicador se les asignó el valor 1 (al resto el valor 0); esto para poder cuantificar los niveles de pobreza por indicador y dimensión.

\section{Calcular el porcentaje de pobreza multidimensional (H), la intensidad (A) y el índice multidimensional de pobreza (IMP)}

Se realizaron los cálculos correspondientes a la incidencia de la pobreza o bien el porcentaje de pobreza multidimensional $(\mathrm{H})$, así como la intensidad $(\mathrm{A})$ — qué tan pobres son los pobres-, y el índice multidimensional de pobreza (IMP), el cual se presenta en la ecuación 2.

$I M P=H * A(\mathbf{2})$

Posteriormente, se realizó una desagregación por comunidad. Los cálculos fueron realizados en el software Stata (versión 14.0). Algunas rutinas de código fueron proporcionadas en la escuela de verano de la Iniciativa de Desarrollo Humano y Pobreza de Oxford (OPHI), centro de investigación y políticas económicas dentro del Departamento de Desarrollo Internacional de Oxford en la Universidad de Oxford. Este centro está dirigido por Sabina Alkire (Oxford Poverty \% Human Development Initiative [OPHI], 2020). En la Figura 1 se aprecia la relación de variables en un diagrama de usos, posteriormente dichas variables son descritas en la tabla 1, acompañadas del peso asignado en cada una para la realización de los cálculos correspondientes. 

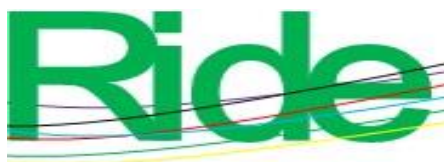

Revista Iberoamericana para la

Figura 1. Variables para medir la pobreza en comunidades rurales

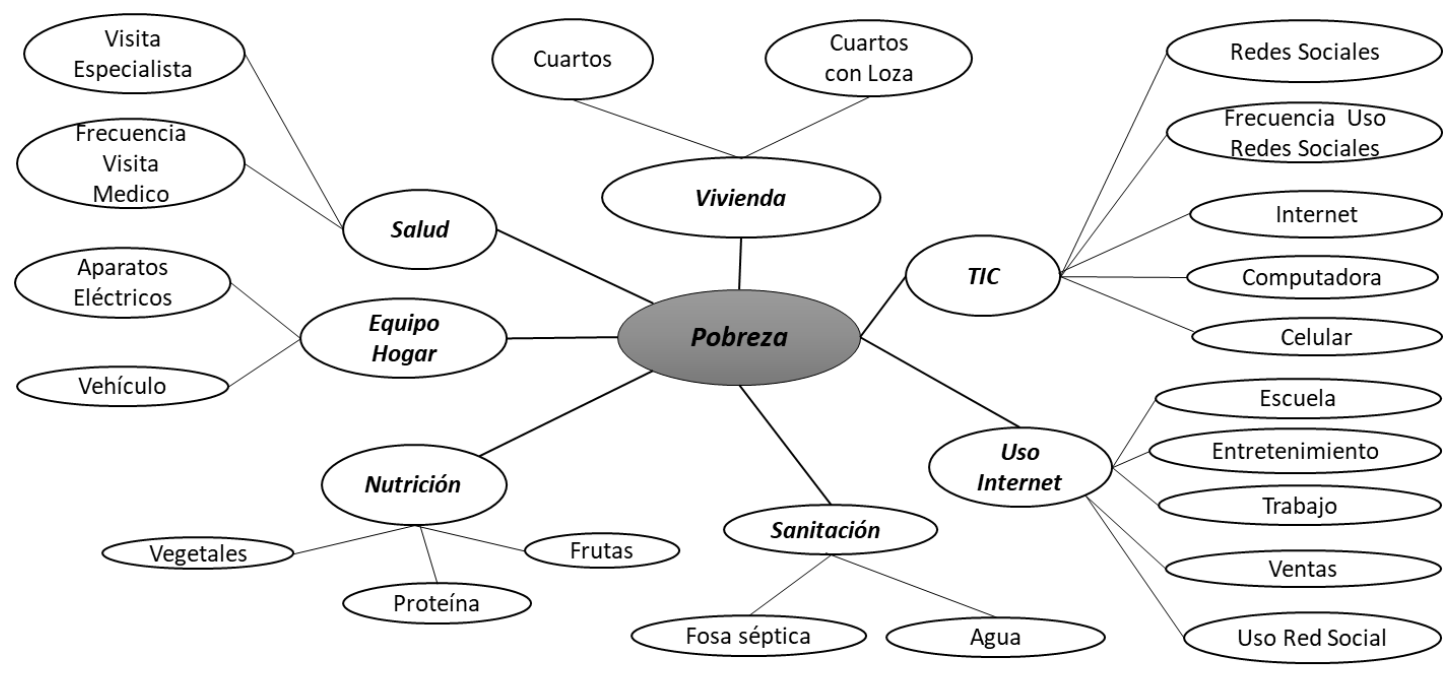

Fuente: Elaboración propia 


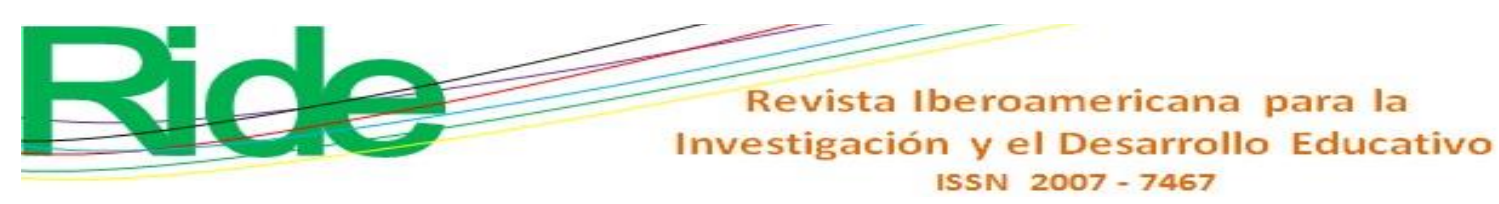

Tabla 1. Dimensiones e indicadores de pobreza

\begin{tabular}{|c|c|c|c|}
\hline Dimensión & Indicador & Descripción & Peso \\
\hline \multirow[t]{2}{*}{$\begin{array}{l}\text { Salud } \\
(10 \%)\end{array}$} & $\begin{array}{l}\text { Visita al médico general } \\
\text { (hdFrViMed) }\end{array}$ & $\begin{array}{l}\text { Un hogar tiene la carencia de visitar al médico general } \\
\text { cuando los integrantes de la familia nunca lo visitan o lo } \\
\text { visitan una vez al año. }\end{array}$ & $5 \%$ \\
\hline & $\begin{array}{l}\text { Visita al médico } \\
\text { especialista } \\
\text { (hdVisespc) }\end{array}$ & $\begin{array}{l}\text { Un hogar tiene la carencia de visitar al médico especialista } \\
\text { cuando nunca lo visitan, aunque lo necesiten por alguna } \\
\text { enfermedad. }\end{array}$ & $5 \%$ \\
\hline \multirow{2}{*}{$\begin{array}{l}\text { Equipo en } \\
\text { el hogar } \\
(20 \%)\end{array}$} & $\begin{array}{l}\text { Aparatos eléctricos } \\
\text { (hdApaElec) }\end{array}$ & $\begin{array}{l}\text { Un hogar tiene la carencia en aparatos eléctricos si cuenta } \\
\text { con menos de tres. }\end{array}$ & $10 \%$ \\
\hline & $\begin{array}{l}\text { Vehículo } \\
\text { (hdCar) }\end{array}$ & $\begin{array}{l}\text { Un hogar tiene la carencia de vehículo si no tiene uno para } \\
\text { transportarse. }\end{array}$ & $10 \%$ \\
\hline \multirow[t]{3}{*}{$\begin{array}{l}\text { Nutrición } \\
(20 \%)\end{array}$} & $\begin{array}{l}\text { Proteína } \\
\text { (hdProteina) }\end{array}$ & $\begin{array}{l}\text { Un hogar tiene la carencia de proteína si los integrantes } \\
\text { comen huevo menos de cuatro veces a la semana, o comen } \\
\text { carne menos de tres veces a la semana, o comen pollo } \\
\text { menos de tres veces a la semana o comen pescado menos } \\
\text { de tres veces a la semana. }\end{array}$ & $6.6 \%$ \\
\hline & $\begin{array}{l}\text { Vegetales } \\
\text { (hdvegetales) }\end{array}$ & $\begin{array}{l}\text { Un hogar tiene la carencia de vegetales si los integrantes } \\
\text { los comen menos de cinco veces a la semana }\end{array}$ & $6.6 \%$ \\
\hline & $\begin{array}{l}\text { Frutas } \\
\text { (hdFrutas) }\end{array}$ & $\begin{array}{l}\text { Un hogar tiene la carencia en frutas si los integrantes las } \\
\text { comen menos de cuatro veces a la semana. }\end{array}$ & $6.6 \%$ \\
\hline \multirow{2}{*}{$\begin{array}{l}\text { Característ } \\
\text { icas de la } \\
\text { vivienda } \\
(10 \%)\end{array}$} & $\begin{array}{l}\text { Habitaciones para dormir } \\
\text { (hdHabit) }\end{array}$ & $\begin{array}{l}\text { Un hogar tiene la carencia en habitaciones utilizadas para } \\
\text { dormir si cuenta con menos de tres. }\end{array}$ & $5 \%$ \\
\hline & $\begin{array}{l}\text { Habitaciones con techo } \\
\text { de loza (hdHabTecho) }\end{array}$ & $\begin{array}{l}\text { Un hogar tiene la carencia en habitaciones de techo con } \\
\text { loza si no tiene ningún cuarto techado con loza. }\end{array}$ & $5 \%$ \\
\hline \multirow{5}{*}{$\begin{array}{l}\text { Hogares } \\
\text { con equipo } \\
\text { de TIC, } \\
\text { acceso a } \\
\text { internet y a } \\
\text { las redes } \\
\text { sociales } \\
(15 \%)\end{array}$} & $\begin{array}{l}\text { Red social } \\
\text { (hdRedSoc) }\end{array}$ & $\begin{array}{l}\text { Un hogar tiene la carencia de redes sociales si los } \\
\text { integrantes no tienen redes sociales y tienen edad para } \\
\text { usarlas. }\end{array}$ & $3 \%$ \\
\hline & $\begin{array}{l}\text { Frecuencia de uso de la } \\
\text { red social } \\
\text { (hdFrecUsRS) }\end{array}$ & $\begin{array}{l}\text { Un hogar tiene la carencia en redes sociales si las usan } \\
\text { menos de tres veces por semana. }\end{array}$ & $3 \%$ \\
\hline & Internet (hdInternet) & $\begin{array}{l}\text { Un hogar tiene la carencia de internet si no cuenta ese } \\
\text { servicio. }\end{array}$ & $3 \%$ \\
\hline & $\begin{array}{l}\text { Computadora } \\
\text { (hdPC) }\end{array}$ & $\begin{array}{l}\text { Un hogar tiene la carencia de computadora si no cuenta } \\
\text { con dicho recurso. }\end{array}$ & $3 \%$ \\
\hline & $\begin{array}{l}\text { Teléfono celular } \\
\text { (hdCelular) }\end{array}$ & $\begin{array}{l}\text { Un hogar tiene la carencia de teléfono móvil si no cuenta } \\
\text { con ese dispositivo. }\end{array}$ & $3 \%$ \\
\hline \multirow{5}{*}{$\begin{array}{l}\text { Uso de } \\
\text { internet } \\
(15 \%)\end{array}$} & $\begin{array}{l}\text { Internet para la escuela } \\
\text { (hdIntEscue) }\end{array}$ & $\begin{array}{l}\text { Un hogar presenta esta carencia si no usa internet para la } \\
\text { escuela. }\end{array}$ & $3 \%$ \\
\hline & $\begin{array}{l}\text { Internet para el } \\
\text { entretenimiento } \\
\text { (hdIntEntrm) }\end{array}$ & $\begin{array}{l}\text { Un hogar tiene esta carencia si no usa el internet para el } \\
\text { entretenimiento. }\end{array}$ & $3 \%$ \\
\hline & $\begin{array}{l}\text { Internet para el trabajo } \\
\text { (hdIntTrab) }\end{array}$ & $\begin{array}{l}\text { Un hogar tiene esta carencia si no usa el internet para el } \\
\text { trabajo. }\end{array}$ & $3 \%$ \\
\hline & $\begin{array}{l}\text { Internet para las redes } \\
\text { sociales (hdDatUsoRS) }\end{array}$ & $\begin{array}{l}\text { Un hogar tiene esta carencia si no usa internet para las } \\
\text { redes sociales. }\end{array}$ & $3 \%$ \\
\hline & $\begin{array}{l}\text { Internet para vender } \\
\text { productos (hdDatVentas) }\end{array}$ & $\begin{array}{l}\text { Un hogar tiene esta carencia si no usa el internet para } \\
\text { vender productos artesanales. }\end{array}$ & $3 \%$ \\
\hline \multirow[t]{2}{*}{$\begin{array}{l}\text { Sanitación } \\
(10 \%)\end{array}$} & $\begin{array}{l}\text { Agua } \\
\text { HdAgua }\end{array}$ & $\begin{array}{l}\text { Un hogar tiene esta carencia si no cuenta con agua en su } \\
\text { casa. }\end{array}$ & $5 \%$ \\
\hline & $\begin{array}{l}\text { Fosa séptica } \\
\text { hdFosaSep }\end{array}$ & $\begin{array}{l}\text { Un hogar presenta esta carencia si no cuenta con fosa } \\
\text { séptica. }\end{array}$ & $5 \%$ \\
\hline
\end{tabular}

Fuente: Elaboración propia 


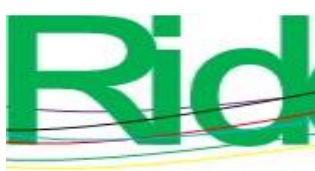

Revista Iberoamericana para la Investigación y el Desarrollo Educativo

ISSN 2007 - 7467

Además, se esbozó un escenario tomando en cuenta si existía una intervención de política pública; para esto, se reasignaron nuevas ponderaciones a las dimensiones e indicadores, lo cual se presenta en la tabla 2.

Tabla 2. Reasignación de ponderaciones a las dimensiones e indicadores

\begin{tabular}{|c|c|c|}
\hline Dimensión & Indicador & Peso \\
\hline \multirow[t]{2}{*}{$\begin{array}{l}\text { Salud } \\
(12 \%)\end{array}$} & $\begin{array}{l}\text { Visita al médico general } \\
\text { (hdFrViMed) }\end{array}$ & $6 \%$ \\
\hline & $\begin{array}{l}\text { Visita al médico especialista } \\
\text { (hdVisespc) }\end{array}$ & $6 \%$ \\
\hline \multirow[t]{2}{*}{$\begin{array}{l}\text { Equipo en el hogar } \\
(25 \%)\end{array}$} & $\begin{array}{l}\text { Aparatos eléctricos } \\
\text { (hdApaElec) }\end{array}$ & $12.5 \%$ \\
\hline & $\begin{array}{l}\text { Vehículo } \\
\text { (hdCar) }\end{array}$ & $12.5 \%$ \\
\hline \multirow[t]{3}{*}{$\begin{array}{l}\text { Nutrición } \\
(21 \%)\end{array}$} & $\begin{array}{l}\text { Proteína } \\
\text { (hdProteina) }\end{array}$ & $7 \%$ \\
\hline & $\begin{array}{l}\text { Vegetales } \\
\text { (hdvegetales) }\end{array}$ & $7 \%$ \\
\hline & $\begin{array}{l}\text { Frutas } \\
\text { (hdFrutas) }\end{array}$ & $7 \%$ \\
\hline \multirow{2}{*}{$\begin{array}{l}\text { Características de la } \\
\text { vivienda } \\
(12 \%)\end{array}$} & $\begin{array}{l}\text { Habitaciones para dormir } \\
\text { (hdHabit) }\end{array}$ & $6 \%$ \\
\hline & Habitaciones con techo de loza (hdHabTecho) & $6 \%$ \\
\hline \multirow{5}{*}{$\begin{array}{l}\text { Hogares con equipo } \\
\text { de } \mathrm{TIC} \text {, acceso a } \\
\text { internet y a las } \\
\text { redes sociales } \\
(5 \%)\end{array}$} & $\begin{array}{l}\text { Red social } \\
\text { (hdRedSoc) }\end{array}$ & $1 \%$ \\
\hline & $\begin{array}{l}\text { Frecuencia de uso de la red social } \\
\text { (hdFrecUsRS) }\end{array}$ & $1 \%$ \\
\hline & Internet (hdInternet) & $1 \%$ \\
\hline & $\begin{array}{l}\text { Computadora } \\
\text { (hdPC) }\end{array}$ & $1 \%$ \\
\hline & $\begin{array}{l}\text { Teléfono celular } \\
\text { (hdCelular) }\end{array}$ & $1 \%$ \\
\hline \multirow[t]{5}{*}{$\begin{array}{l}\text { Uso de internet } \\
(15 \%)\end{array}$} & $\begin{array}{l}\text { Internet para la escuela } \\
\text { (hdIntEscue) }\end{array}$ & $3 \%$ \\
\hline & $\begin{array}{l}\text { Internet para el entretenimiento } \\
\text { (hdIntEntrm) }\end{array}$ & $3 \%$ \\
\hline & $\begin{array}{l}\text { Internet para el trabajo } \\
\text { (hdIntTrab) }\end{array}$ & $3 \%$ \\
\hline & $\begin{array}{l}\text { Internet para las redes sociales } \\
\text { (hdDatUsoRS) }\end{array}$ & $3 \%$ \\
\hline & $\begin{array}{l}\text { Internet para vender productos } \\
\text { hdDatVentas }\end{array}$ & $3 \%$ \\
\hline \multirow[t]{2}{*}{$\begin{array}{l}\text { Sanitación } \\
(10 \%)\end{array}$} & $\begin{array}{l}\text { Agua } \\
\text { hdAgua }\end{array}$ & $5 \%$ \\
\hline & $\begin{array}{l}\text { Fosa séptica } \\
\text { hdFosaSep }\end{array}$ & $5 \%$ \\
\hline
\end{tabular}

Fuente: Elaboración propia

La hipótesis planteada fue la siguiente: un índice multidimensional de pobreza es un indicador que funciona como medida para comparar indicadores de pobreza. 


\section{Revista Iberoamericana para la Investigación y el Desarrollo Educativo ISSN 2007 - 7467}

\section{Resultados}

En la tabla 3 se presentan las medidas agregadas de la incidencia e intensidad según el porcentaje de la línea de pobreza, así como el índice multidimensional de pobreza. De igual forma, en la tabla 4 se presenta la pobreza unidimensional, la pobreza multidimensional y el porcentaje de contribución a la pobreza multidimensional.

Tabla 3. Pobreza unidimensional

\begin{tabular}{|c|c|c|c|}
\hline $\begin{array}{c}\text { Línea de } \\
\text { pobreza (k) }\end{array}$ & $\begin{array}{c}\text { Incidencia } \\
(\mathbf{H}) \%\end{array}$ & $\begin{array}{c}\text { Intensidad } \\
(\mathbf{A}) \%\end{array}$ & $\begin{array}{c}\text { Índice multidimensional } \\
\text { de pobreza (IMP) }\end{array}$ \\
\hline $10 \%$ & $99.19 \%$ & $55.29 \%$ & 0.548 \\
\hline $20 \%$ & $98.39 \%$ & $55.97 \%$ & 0.551 \\
\hline $30 \%$ & $87.71 \%$ & $55.67 \%$ & 0.488 \\
\hline $40 \%$ & $73.44 \%$ & $64.69 \%$ & 0.475 \\
\hline $50 \%$ & $63.43 \%$ & $67.99 \%$ & 0.431 \\
\hline $60 \%$ & $43.91 \%$ & $67.98 \%$ & 0.299 \\
\hline $70 \%$ & $26.52 \%$ & $73.51 \%$ & 0.195 \\
\hline $80 \%$ & $10.16 \%$ & $86.68 \%$ & 0.088 \\
\hline $90 \%$ & $4.30 \%$ & $91.06 \%$ & 0.039 \\
\hline $100 \%$ & $0.00 \%$ & NA & 0.000 \\
\hline
\end{tabular}

Fuente: Elaboración propia 


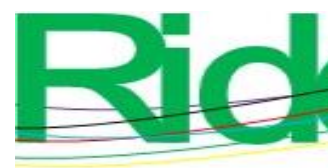

Revista Iberoamericana para la Investigación y el Desarrollo Educativo ISSN 2007 - 7467

Tabla 4. Pobreza multidimensional y porcentaje de contribución a la pobreza

\begin{tabular}{|c|c|c|c|c|}
\hline Dimensión & Indicador & $\begin{array}{c}\text { Pobreza } \\
\text { unidimensional } \\
(\%)\end{array}$ & $\begin{array}{c}\text { Pobreza } \\
\text { multidimensional } \\
(\%)\end{array}$ & $\begin{array}{c}\text { Contribución al } \\
\text { índice } \\
\text { multidimensional de } \\
\text { pobreza }(\%)\end{array}$ \\
\hline \multirow{2}{*}{ Salud } & HdFrViMed & 69.8 & 32.72 & 6.49 \\
\hline & HdVisespc & 77.33 & 39.15 & 7.76 \\
\hline \multirow{2}{*}{$\begin{array}{c}\text { Equipo en el } \\
\text { hogar }\end{array}$} & hdApaElec & 55.4 & 38.35 & 15.21 \\
\hline & HdCar & 68.53 & 37.26 & 14.77 \\
\hline \multirow{3}{*}{ Nutrición } & hdProteina & 60.12 & 28.42 & 7.51 \\
\hline & hdvegetales & 36.11 & 23.83 & 6.3 \\
\hline & hdFrutas & 32.61 & 19.29 & 5.1 \\
\hline \multirow{2}{*}{$\begin{array}{l}\text { Características } \\
\text { de la vivienda }\end{array}$} & HdHabit & 50.62 & 30.31 & 6.01 \\
\hline & hdHabTecho & 26 & 20.66 & 4.1 \\
\hline \multirow{5}{*}{$\begin{array}{l}\text { Hogares con } \\
\text { equipo de TIC, } \\
\text { acceso a } \\
\text { internet y a las } \\
\text { redes sociales }\end{array}$} & HdRedSoc & 60.93 & 37.26 & 1.48 \\
\hline & HdFrecUsRS & 64.14 & 37.26 & 1.48 \\
\hline & HdInternet & 96.79 & 40.76 & 1.62 \\
\hline & HdPC & 80.49 & 40.76 & 1.62 \\
\hline & hdCelular & 21.32 & 14.42 & 0.57 \\
\hline \multirow{5}{*}{ Uso de internet } & HdIntEscuela & 93.58 & 40.76 & 3.23 \\
\hline & HdIntEntrm & 80.49 & 37.54 & 2.98 \\
\hline & HdIntTrab & 95.18 & 40.76 & 3.23 \\
\hline & HdDatUsoRS & 73.26 & 38.35 & 3.04 \\
\hline & hdDatVentas & 91.97 & 40.76 & 3.23 \\
\hline \multirow{2}{*}{ Sanitación } & HdAgua & 21.29 & 15.38 & 3.05 \\
\hline & hdFosaSep & 8.56 & 6.15 & 1.22 \\
\hline
\end{tabular}

Fuente: Elaboración propia

En la tabla 5 se presentan la población, la incidencia, la intensidad y el índice multidimensional de pobreza por comunidad; para ello, se estableció como valor $k$ de línea de pobreza igual a $50 \%$, de tal forma que se aprecia un nuevo valor para el índice y se percibe que la comunidad de La Unión es la más afectada por la pobreza. Asimismo, en la tabla 6 se presenta el porcentaje de contribución a la pobreza por región. 


\section{Revista Iberoamericana para la Investigación y el Desarrollo Educativo ISSN 2007 - 7467}

Tabla 5. Índice multidimensional de pobreza por comunidad

\begin{tabular}{|c|c|c|c|c|}
\hline Comunidad & $\begin{array}{c}\text { Población } \\
\mathbf{\%}\end{array}$ & $\begin{array}{c}\text { Incidencia } \\
\mathbf{\%}(\mathbf{H})\end{array}$ & $\begin{array}{c}\text { Intensidad } \\
\mathbf{\%}(\mathbf{A})\end{array}$ & $\begin{array}{c}\text { Índice } \\
\text { multidimensional de } \\
\text { pobreza (IMP) }\end{array}$ \\
\hline La Unión & 8.81 & 87.50 & 64.00 & 0.56 \\
\hline Las Flores & 9.43 & 27.78 & 66.00 & 0.18 \\
\hline Tepelmeme & 81.76 & 37.25 & 60.98 & 0.23 \\
\hline Municipal & 100 & 40.76 & 61.87 & 0.25 \\
\hline
\end{tabular}

Fuente: Elaboración propia

Tabla 6. Porcentaje de contribución por región

\begin{tabular}{|c|c|c|c|c|}
\hline Indicador & Las Flores & Tepelmeme & La Unión & Municipal \\
\hline hdFrViMed & 6.06 & 6.47 & 6.70 & 6.49 \\
\hline hdVisespc & 7.58 & 7.77 & 7.81 & 7.76 \\
\hline hdApaElec & 15.15 & 15.10 & 15.63 & 15.21 \\
\hline hdCar & 15.15 & 15.10 & 13.39 & 14.77 \\
\hline hdProteina & 8.08 & 7.48 & 7.44 & 7.51 \\
\hline hdvegetales & 10.10 & 6.04 & 5.95 & 6.30 \\
\hline hdFrutas & 6.06 & 5.18 & 4.46 & 5.10 \\
\hline hdHabit & 4.55 & 6.26 & 5.58 & 6.01 \\
\hline hd HabTecho & 1.52 & 4.53 & 3.35 & 4.10 \\
\hline hdRedSoc & 1.52 & 1.51 & 1.34 & 1.48 \\
\hline hdFrecUsRS & 1.52 & 1.51 & 1.34 & 1.48 \\
\hline hdInternet & 1.52 & 1.64 & 1.56 & 1.62 \\
\hline hdPC & 1.52 & 1.64 & 1.56 & 1.62 \\
\hline hdCelular & 1.52 & 0.52 & 0.45 & 0.57 \\
\hline hdIntEscuela & 3.03 & 3.28 & 3.13 & 3.23 \\
\hline hdIntEntrm & 3.03 & 2.93 & 3.13 & 2.98 \\
\hline hdIntTrab & 3.03 & 3.28 & 3.13 & 3.23 \\
\hline hdDatUsoRS & 3.03 & 3.02 & 3.13 & 3.04 \\
\hline hdDatVentas & 3.03 & 3.28 & 3.13 & 3.23 \\
\hline hdAguar & 0.00 & 2.37 & 6.70 & 3.05 \\
\hline hdFosaSep & 3.03 & 1.08 & 1.12 & 1.22 \\
\hline
\end{tabular}

Fuente: Elaboración propia 


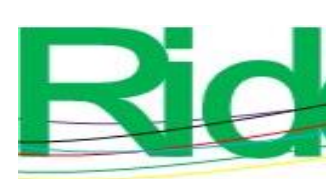

Revista Iberoamericana para la
Investigación y el Desarrollo Educativo
ISSN $2007-7467$

\section{Intervención de política pública}

Se propone que el gobierno realice una intervención y reasigne su presupuesto (tal y como se indica en la tabla 2) para los indicadores que presentan mayores índices de pobreza. En concordancia con esta idea, se realizó una reasignación dando una mayor ponderación a las dimensiones de salud, equipo en el hogar, nutrición, características de la vivienda, y una menor ponderación a las TIC y el internet. Hecho esto, se volvieron a realizar todos los cálculos, lo que lograría reducir la pobreza en caso de llevarse a cabo. Por eso, en las figuras 2 y 3 se presentan comparativos de incidencia e intensidad de la pobreza con valores originales y con valores de la intervención pública; asimismo, en la figura 4 se tiene el índice multidimensional de la pobreza, el cual es menor con dicha intervención.

Figura 2. Comparación de incidencia de la pobreza

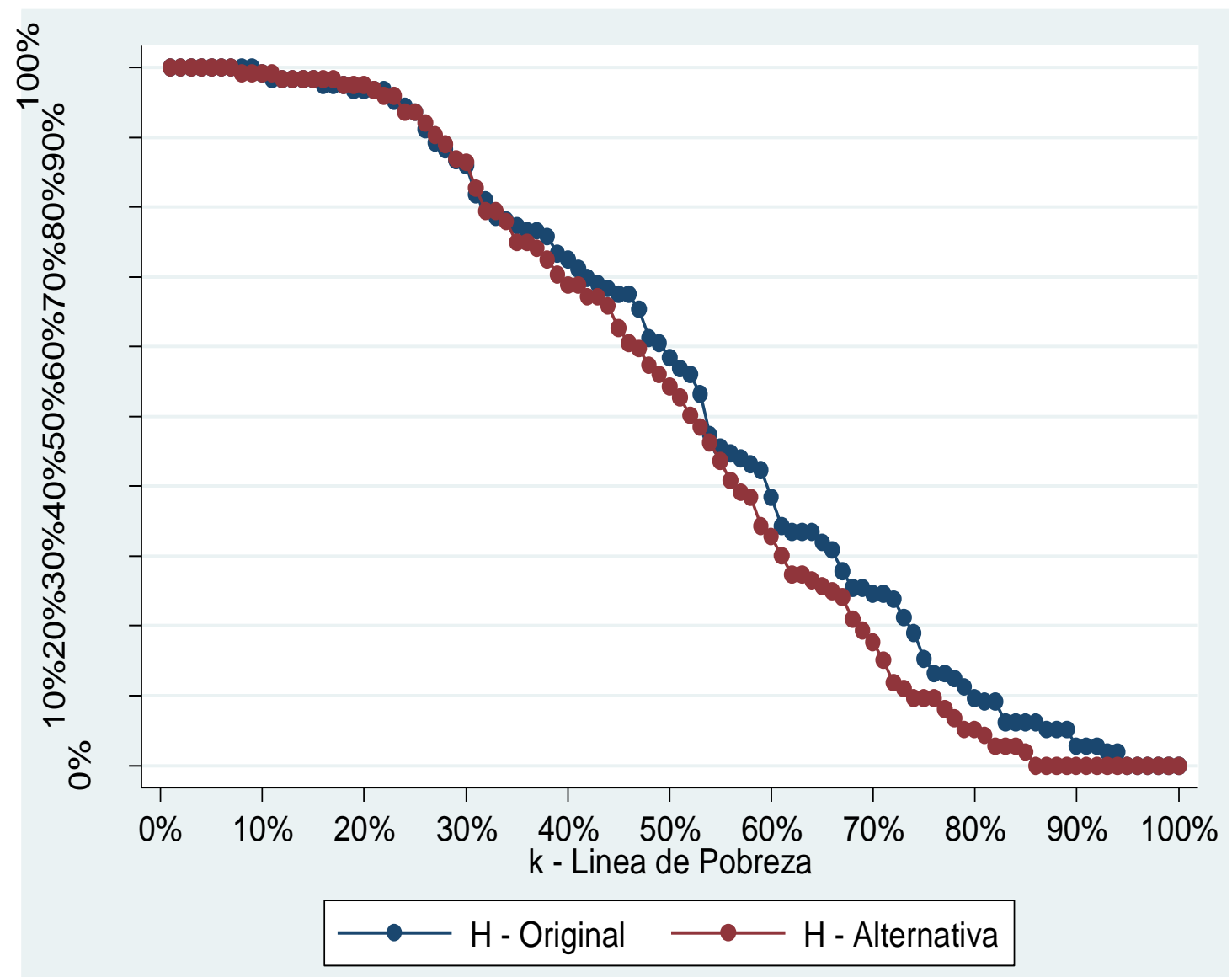

Fuente: Elaboración propia 

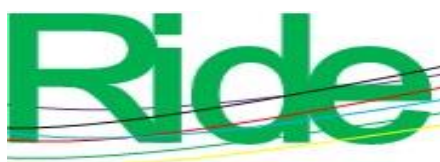

Revista Iberoamericana para la Investigación y el Desarrollo Educativo ISSN 2007 - 7467

Figura 3. Comparación de intensidad de la pobreza

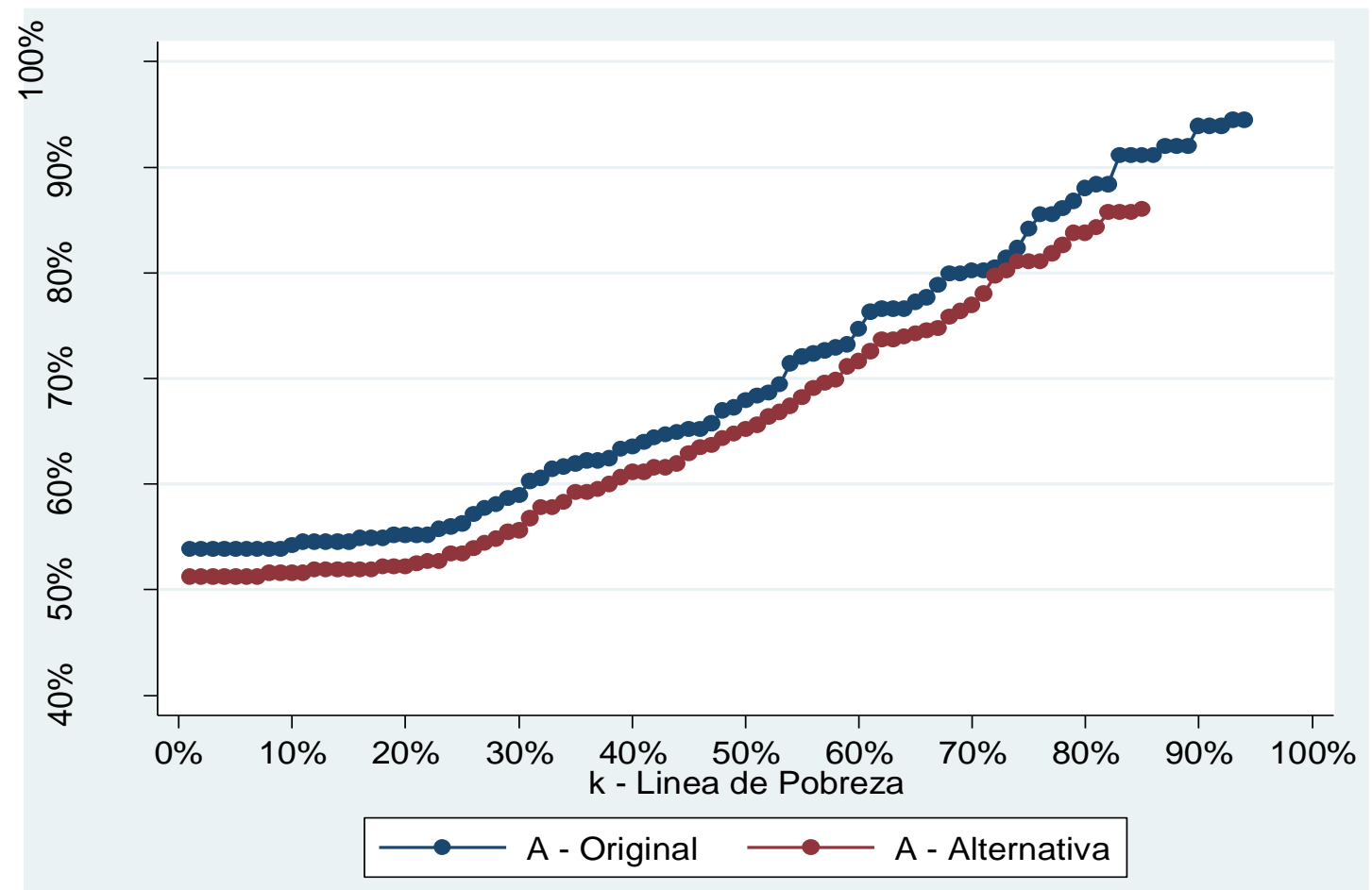

Fuente: Elaboración propia

Figura 4. Comparación del índice multidimensional de pobreza

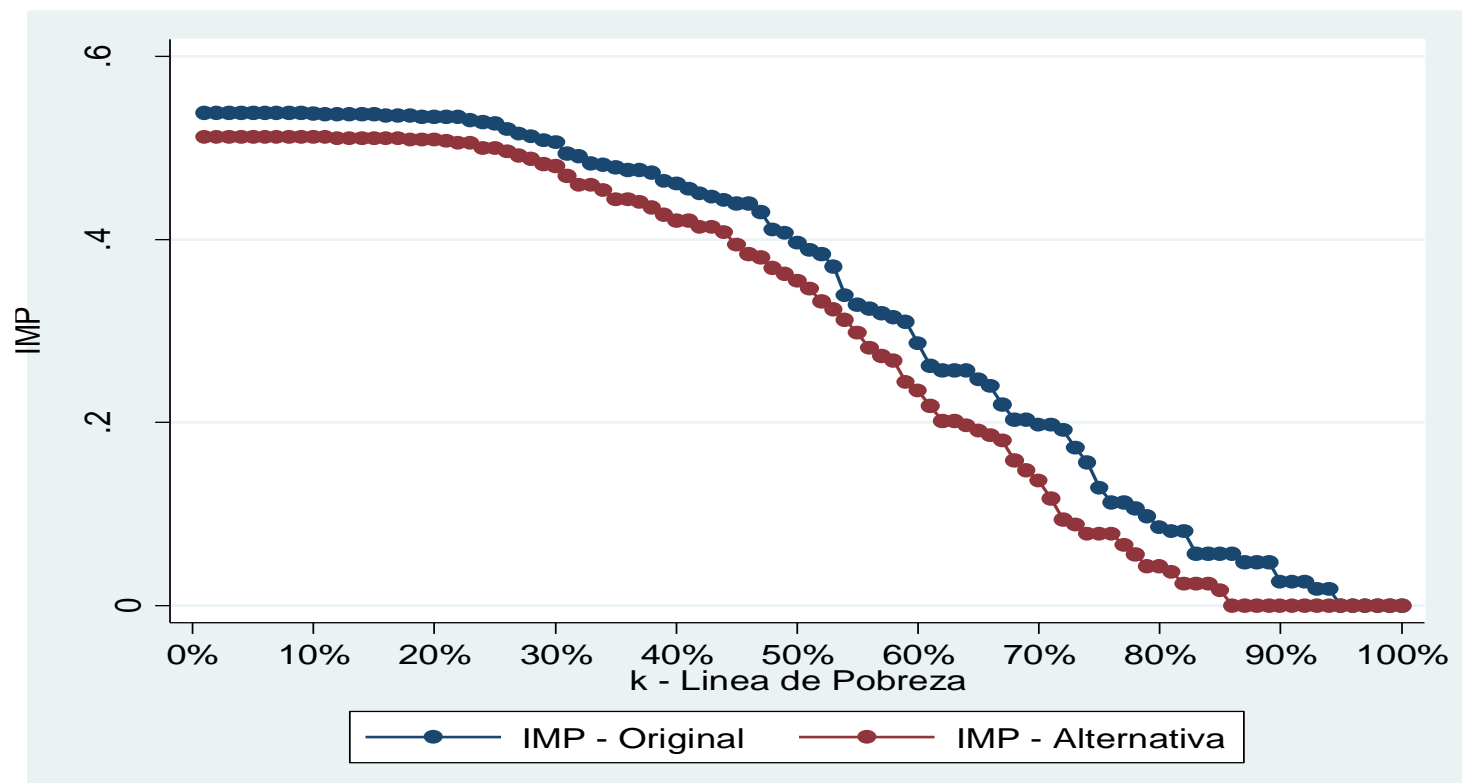

Fuente: Elaboración propia 


\section{Discusión}

En los resultados se encontró que el índice multidimensional de pobreza del municipio de Tepelmeme Villa de Morelos del estado de Oaxaca tenía un valor promedio de $0.431(\mathrm{k}=50 \%)$, lo cual es alto en comparación con el reportado por el índice mundial de pobreza (Alkire, Kanagaratnam y Suppa, 2019). Sin embargo, vale acotar que existen algunas variantes, pues en este caso se consideraron 21 indicadores, incluyendo las TIC. En cambio, por estandarización, en el índice mundial de pobreza se consideran 10 indicadores. Aun así, lo importante es tener una métrica para poder realizar comparaciones.

De forma inicial, en la tabla 4 se tiene el índice unidimensional de pobreza — es decir, los porcentajes de pobreza de cada indicador-, y se percibe que lo más grave en el municipio tiene que ver con el internet en los hogares, así como su uso en la escuela, en el trabajo y en las ventas, aunque también resaltan los aspectos de salud. Por otro lado, al utilizar la metodología de Alkire y Foster (Alkire y Foster, 2011), los indicadores de pobreza tienen otro comportamiento, pues su evaluación se realiza de forma multidimensional. En tal sentido, los porcentajes disminuyen en casi la mitad; por ejemplo, para el caso del internet, este era de forma unidimensional de $96.79 \%$, mientras que de forma multidimensional fue de $40.76 \%$.

En la misma tabla 4 se tiene en porcentajes la columna de contribución al índice multidimensional de pobreza. Aquí es donde se debe analizar cuáles son los indicadores que más afectan al índice (de hecho, se hallaron otros indicadores importantes; véanse los colores en rojo y naranja de la tabla). En síntesis, se aprecia que lo más grave es el equipamiento del hogar (número de aparatos eléctricos y automóvil), además de la salud (frecuencia de visitas al médico general y al médico especialista), así como de nutrición o alimentación (proteína, vegetales y frutas), además de las características de la vivienda (número de habitaciones para dormir y habitaciones con techo de loza). El resto de indicadores de TIC no afectan al índice, mientras que el uso del internet se mantiene en estado de alerta, pero no es grave.

En la tabla 5 se tiene la población, la incidencia, la intensidad y el índice multidimensional de pobreza por comunidad. Se observa que la comunidad más afectada es La Unión, ya que presenta el índice más alto, mientras que la menos afectada es Las Flores. Asimismo, en la tabla 6 se ofrece la contribución al índice por región o comunidad. Para la región Las Flores lo más grave es el equipamiento en el hogar (número de aparatos eléctricos y automóvil), seguido de alimentación (vegetales) y después salud (visita al médico especialista). Para la región Tepelmeme lo más grave es el equipamiento en el hogar (número 


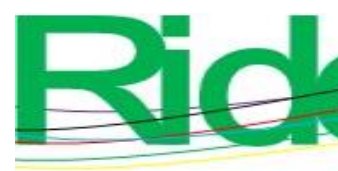

Revista Iberoamericana para la
Investigación y el Desarrollo Educativo
ISSN $2007-7467$

de aparatos eléctricos y automóvil), después salud (visita al médico general y al especialista) y alimentación en cuanto a proteína (también tiene alertas por las carencias de vegetales y la falta de habitaciones para dormir). Para el caso de la región La Unión los patrones de los indicadores son similares, pues lo más grave está en el equipamiento en el hogar, la salud, la alimentación y la falta de habitaciones para dormir.

Con los datos presentados en las tablas 4 y 5 se planteó una intervención de política pública. Para ello, se realizó una reasignación de las ponderaciones a los indicadores, lo que permitió disminuir la incidencia, la intensidad y el índice multidimensional de pobreza. En tal sentido, es importante que tanto el gobierno del estado como el gobierno municipal realicen una reasignación de sus partidas presupuestales relacionadas con las variables de mayor porcentaje de contribución al índice de la pobreza (equipamiento en el hogar, salud y alimentación) para disminuir la pobreza.

Esas reasignaciones deben ejecutarse con calidad, es decir, tiene que existir eficiencia en la distribución de recursos, para lo cual se debe contar con personal capacitado en programas de salud, sociales y de estudios, pues con estas acciones se podrá disminuir la pobreza en este municipio, así como en otros cercanos (Leija y Saltillo, 2019; Sano et al., 2019; Zhou y Liu, 2019).

Por otra parte, vale indicar que uno de los indicadores que afectan al índice de pobreza en el municipio de Tepelmeme Villa de Morelos es el equipamiento en el hogar. Por ello, el gobierno puede coordinar con el Banco Mundial alguna acción en el marco del Proyecto de Expansión de Finanzas Rurales para ayudar al sistema crediticio de zonas donde la presencia de la banca tradicional es escasa o nula. Al respecto, es importante mencionar que se han concedido más de 150000 préstamos y se amplió el crédito para las empresas rurales de pequeña escala, con especial énfasis en las mujeres y en las zonas marginadas (Banco Mundial, 2019).

Por otro lado, no se debe descuidar el uso del internet en el municipio, pues — aunque no aporta a la pobreza un porcentaje mayor a $3.23 \%$ - sí presenta alertas; además, hay que recordar que el internet es un detonador para la economía digital (Mittal y Mehar, 2016). En efecto, las TIC ayudan a la adquisición de materiales (Pullanikkatil, 2019), así como a revisar los pronósticos del tiempo para las actividades agrícolas, lo que permite tomar medidas preventivas para una mejor cosecha (Liu et al., 2018).

En los años 2016 y 2018 se observó en Oaxaca una mejora, principalmente, en cuanto al acceso a los servicios básicos; por ejemplo, más personas cuentan con acceso al agua 


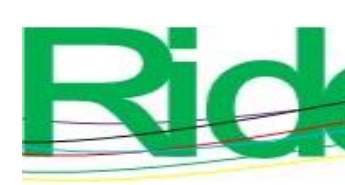

Revista Iberoamericana para la
Investigación y el Desarrollo Educativo
ISSN $2007-7467$

entubada dentro del terreno y a la electricidad (Coneval, 2019). No obstante, hace falta atender otras prioridades como la salud y la nutrición (Eigbiremolen y Ogbuabor, 2018; Sano et al., 2019).

En definitiva, con la creación del índice multidimensional de pobreza se pueden tomar acciones más eficaces (Padda y Hameed, 2018) según las regiones más necesitadas (Bernard et al., 2019). Sin embargo, como se dijo anteriormente, estas políticas deben ser claras y enfocadas tanto a los proveedores como a los receptores del recurso.

Asimismo, es pertinente indicar que este estudio se puede replicar para optimizar la intervención de políticas públicas en municipios con características similares, aunque se debe hacer énfasis en que para ver la eficiencia de la gestión del municipio por usos y costumbres, se requiere dar un seguimiento a los indicadores de pobreza a corto plazo para poder medir la eficiencia de la gestión. Por ello, se considera pertinente investigar más acerca de la eficiencia de las políticas, puesto que el presente estudio solo tuvo como finalidad la creación de un índice para la generación de la política pública para disminuir la pobreza.

Finalmente, las limitaciones de esta investigación se hallan en la clasificacion por género y grupos de edad, dado que para ello se requiere ampliar la investigación a pobreza de la población, y no de los hogares. La fortaleza de este estudio, en cambio, es que se cuenta con una métrica por hogares en un municipio considerado como rural por la cantidad de habitantes. La áreas de debilidad fueron no habler incluido la cohesion social, pues en estos lugares se acostumbran muchas reuniones con amistades, así como la falta de indicadores de rezago educativo. Otra debilidad es que el analizar solo al municipio citado de Tepelmeme con sus dos comunidades (La Unión y Las Flores), los resultados no son representativos a nivel nacional. Aun así, las conclusiones pueden ser extensivas a otros municipios cercanos con características sociales y económicas similares.

\section{Conclusiones}

El índice multidimensional de pobreza en el municipio de Tepelmeme Villa de Morelos es una medida que incluye la incidencia e intensidad de la pobreza tanto en la cabecera municipal como en dos comunidades (La Unión y Las Flores). Este puede ser utilizado para analizar el porcentaje de pobreza por indicador de forma multidimensional, así como para examinar el porcentaje de contribución al índice de pobreza de cada indicador, lo cual invita a tomar medidas en el ámbito por una gestión municipal que debe seguir estándares de efectividad y eficiencia. 


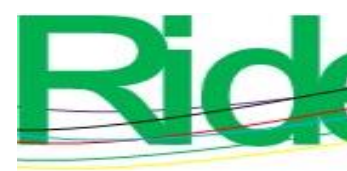

Revista Iberoamericana para la
Investigación y el Desarrollo Educativo
ISSN $2007-7467$

De forma general, según los datos recabados, se puede concluir que los indicadores que más influyen en la pobreza son las carencias de equipamiento en el hogar (número de aparatos eléctricos con $15.21 \%$ y automóvil con $14.77 \%$ ), las deficiencias de salud (visita al médico especialista con $7.76 \%$ ) y la carencia de nutrición (proteína con $7.51 \%$ ). De igual forma, la carencia de acceso a la salud en cuanto a la frecuencia de visita al médico general $(6.49 \%)$, nutrición en cuanto a vegetales $(6.3 \%)$ y habitaciones para dormir $(6.01 \%)$. El resto de indicadores fueron menores a $5 \%$.

Finalmente, los indicadores de la dimensión Hogares con equipo de TIC, acceso a internet y a las redes sociales fueron los de menores porcentajes de contribución al índice multidimensional de pobreza. Asimismo, la dimensión Uso de internet presenta indicadores con un porcentaje de contribución al índice bajo en promedio de $3 \%$. Por ello, se efectuó un ajuste en las ponderaciones de los indicadores para simular un escenario de intervención del gobierno, con lo que se logró disminuir la incidencia, la intensidad y el índice multidimensional de la pobreza.

\section{Futuras Líneas de Investigación}

Se exhorta a continuar con investigaciones acerca del ponderador de Hogares con equipo de $T I C$, acceso a internet y a las redes sociales, debido a que acorde con la literatura de organismos de carácter internacional como lo son la Organización de las Naciones Unidas (ONU) y la Organización para la Cooperación y Desarrollo Económico (OCDE), han hecho gran énfasis en que el desarrollo tecnológico es primordial para el desarrollo económico, por lo tanto resulta interesante analizar los factores que hacen que los resultados en esta investigación tengan un impacto menor.

Asimismo, resulta importante continuar con investigaciones acerca del impacto de las TIC en la pobreza, segmentando las muestras por género o por edad. Se alienta a los lectores a hacer uso de la técnica de Alkire y Foster para la creación de diferentes índices de impacto en la pobreza. Sin embargo, también es de gran interés medir el impacto de las políticas públicas en la pobreza, bajo la misma metodología de Alkire y Foster. 


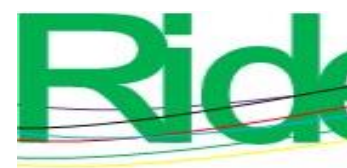

Revista Iberoamericana para la Investigación y el Desarrollo Educativo ISSN $2007-7467$

\section{Referencias}

Aguilar-Estrada, A. E., Caamal-Cahuicho, I. y Portillo-Vázquez, M. (2018a). Políticas públicas para los municipios más pobres de México. Estudios Sociales. Revista de Alimentación Contemporánea y Desarrollo Regional, 28(51).

Aguilar Estrada, A. E., Caamal-Cauicho, I. y Portillo-Vázquez, M. (2018b). Intensidades de pobreza multidimensional en México a nivel municipal. Revista Mexicana de Ciencias Agrícolas, 9(1), 251-258.

Alkire, S., Kanagaratnam, U. and Suppa, N. (2019). The Global Multidimensional Poverty Index (MPI) 2019. Oxford Poverty and Human Development Initiative, University of Oxford.

Alkire, S., Apablaza, M., Chakravarty, S. and Yalonetzky, G. (2017). Measuring chronic multidimensional poverty. Journal of Policy Modeling, 39(6), 983-1006.

Alkire, S. and Foster, J. (2011). Counting and multidimensional poverty measurement. Journal of Public Economics, 95(7), 476-487.

Banco Mundial (2019). Informe Anual 2019li. Informe Anual 2019, 1-95.

Becerril-Velasco, C. I. (2019). The feeble institutional link between the information and communication technologies ( ICTs ) and poverty in Mexico. Nóesis. Revista de Ciencias Sociales y Humanidades, 28,43-61.

Becerril-Velasco, C. I. (2020). Pobreza urbana y apropiación de las tecnologías de la información y comunicación (TIC) en México. Observatorio, 14(2).

Bernard, J., Contzen, S., Decker, A. y Shucksmith, M. (2019). Poverty and Social Exclusion in Diversified Rural Contexts. Sociologia Ruralis, 59(3), 353-368.

Campos Vázquez, R. M. y Monroy-Gómez-Franco, L. A. (2016). La relación entre crecimiento económico y pobreza en México. Investigacion Economica, 75(298), 77113.

Comisión Económica para América Latina y el Caribe [Cepal] (2013). Mujeres indígenas en América Latina: dinámicas demográficas y sociales en el marco de los derechos humanos. Naciones Unidas.

Chávez, C. y Carrera, C. (2016). Pobreza rural y PROCAMPO: un análisis comparativo de dos municipios de Chihuahua. SSOAR, 23(2), 134-144.

Clausen, J., Vargas, S. and Barrantes, N. (2019). Do official multidimensional poverty measures in Latin America reflect the priorities of people living in poverty? Ensayos de Politica Economica, 2(6), 15-34. Recuperado de 


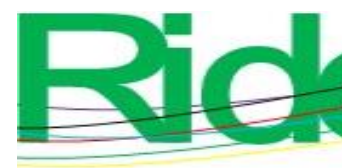

Revista Iberoamericana para la
Investigación y el Desarrollo Educativo
ISSN $2007-7467$

http://wadmin.uca.edu.ar/public/ckeditor/CienciasEconómicas/Depto.Investigación/ documentos-archivos/rEPE2018A2.pdf

Consejo Nacional de Evaluación de la Política de Desarrollo Social [Coneval] (2015). Consulta dinámica de resultados de pobreza a nivel municipio 2010 Y 2015. Recuperado de https://www.coneval.org.mx/Medicion/Paginas/consultapobrezamunicipal.aspx

Consejo Nacional de Evaluación de la Política de Desarrollo Social [Coneval] (2019). 10 años de medición de pobreza en México, avances y retos de política social Oaxaca. Recuperado de https://www.coneval.org.mx/SalaPrensa/Comunicadosprensa/Documents/2019/CO MUNICADO10MEDICIONPOBREZA20082018.pdf

Eigbiremolen, G. O. and Ogbuabor, J. E. (2018). Measurement and determinants of food poverty: A dynamic analysis of Nigeria's first panel survey data. African Development Review, 30(4), 423-433.

Hissa, H. R., Alves Filho, N. T., Costa, M., Strauch, G., Bassi, L. y Linhares de Assis, R. (2019). Sustainable Rural Development in Rio de Janeiro State: The Rio Rural Program. 23-39.

Huerta Barrientos, A., Vera Morales, A. E. y Vázquez González, T. (2018). Mexican Rural Communities' Metabolism and Its Impact on Socioeconomic Indicators. Culture and Identity (pp. 41-56).

Leija, H. C. and Saltillo, D. (2019). Sociodemographic Effects on Municipal Poverty in Mexico . Revista de Economía, 36(92), 129-163.

Liu, Wei, Xu, J., Li, J. and Li, S. (2019). Rural Households' Poverty and Relocation and Settlement: Evidence from Western China. International Journal of Environmental Research and Public Health, 16(14).

Liu, Wenxin, Zhao, M. and Xu, T. (2018). Water poverty in rural communities of arid areas in China. Water (Switzerland), 10(4).

Long, A. S., Hanlon, A. L. and Pellegrin, K. L. (2018). Socioeconomic variables explain rural disparities in US mortality rates: Implications for rural health research and policy. SSM - Population Health, 6,72-74.

Mittal, S. and Mehar, M. (2016). Socio-economic Factors Affecting Adoption of Modern Information and Communication Technology by Farmers in India: Analysis Using Multivariate Probit Model. The Journal of Agricultural Education and Extension, 


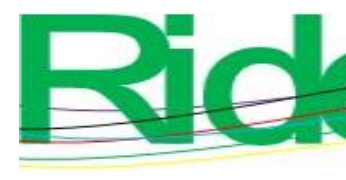

22(2), 199-212.

Naciones Unidas (2020). Objetivos de desarrollo sostenible. Recuperado de https://www.un.org/sustainabledevelopment/es/poverty/

Nguyen, P. T. and Wells, S. (2018). Systemic Indicators for Rural Communities in Developing Economies: Bringing the Shared Vision into Being. Systemic Practice and Action Research, 31(2), 159-177.

Oxford Poverty \% Human Development Initiative [OPHI] (2020). The 2019 Cohort Completes their Training at the OPHI Summer School in Mexico City. OPHI. Retrieved from https://ophi.org.uk/about/

Padda, I. U. H. and Hameed, A. (2018). Estimating multidimensional poverty levels in rural Pakistan: A contribution to sustainable development policies. Journal of Cleaner Production, 197,435-442.

Pullanikkatil, D., S. C. M. (2019). Poverty Reduction Through Non-Timber Forest Products: Personal Stories. In Shackleton, C. M. (ed.), Poverty Reduction Through Non-Timber Forest Products (pp. 153-160). Springer, Cham.

Roberts, E., Beel, D., Philip, L. and Townsend, L. (2017). Rural resilience in a digital society: Editorial. Journal of Rural Studies, 54,355-359.

Rotz, S., Gravely, E., Mosby, I., Duncan, E., Finnis, E., Horgan, M., LeBlanc, J., Martin, R., Neufeld, H. T., Nixon, A., Pant, L., Shalla, V. and Fraser, E. (2019). Automated pastures and the digital divide: How agricultural technologies are shaping labour and rural communities. Journal of Rural Studies, 68,112-122.

Sano, Y., Routh, B. and Lanigan, J. (2019). Food parenting practices in rural poverty context. Appetite, 135, 115-122.

Teruel, G., Reyes, M., Minor, E. and López, M. (2018). Mexico: Not a middle class but a poverty country. Analyzing middle class performance in between 2000-2014. Trimestre Economico, 85(339), 447-480.

Van Dijk, J. A. (2017). Digital divide: Impact of access. The International Encyclopedia of Media Effects, 1-11.

Zhou, Y. and Liu, Y. (2019). The geography of poverty: Review and research prospects. Journal of Rural Studies. Retrieved from https://www.sciencedirect.com/science/article/abs/pii/S0743016718303899 https://doi.org/10.1016/j.jrurstud.2019.01.008 


\begin{tabular}{|c|c|}
\hline 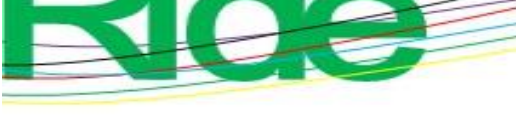 & $\begin{array}{l}\text { Revista Iberoamericana para la } \\
\text { Investigación y el Desarrollo Educativo } \\
\text { ISSN } 2007-7467\end{array}$ \\
\hline Rol de Contribución & Autor (es) \\
\hline Conceptualización & Martha Jiménez García \\
\hline Metodología & Martha Jiménez García \\
\hline Software & Martha Jiménez García \\
\hline Validación & $\begin{array}{l}\text { Martha Jiménez García «igual», Ingrid Anai Hernández Horta } \\
\text { «igual» }\end{array}$ \\
\hline Análisis Formal & Martha Jiménez García \\
\hline Investigación & $\begin{array}{l}\text { Martha Jiménez García «igual», Ingrid Anai Hernández Horta } \\
\text { «igual», María Elena Tavera Cortes «igual» }\end{array}$ \\
\hline Recursos & Martha Jiménez García \\
\hline Curación de datos & Martha Jiménez García \\
\hline $\begin{array}{l}\text { Escritura - Preparación del } \\
\text { borrador original }\end{array}$ & $\begin{array}{l}\text { Martha Jiménez García «igual», Ingrid Anai Hernández Horta } \\
\text { «igual» }\end{array}$ \\
\hline $\begin{array}{l}\text { Escritura - Revisión y } \\
\text { edición }\end{array}$ & $\begin{array}{l}\text { Martha Jiménez García «igual», Ingrid Anai Hernández Horta } \\
\text { «igual» }\end{array}$ \\
\hline Visualización & Martha Jiménez García \\
\hline Supervisión & Martha Jiménez García \\
\hline $\begin{array}{l}\text { Administración de } \\
\text { Proyectos }\end{array}$ & Martha Jiménez García \\
\hline Adquisición de fondos & Martha Jiménez García \\
\hline
\end{tabular}

